\begin{tabular}{lll}
\hline Gwenda & 1 & \\
Vleeshouwers, & $\begin{array}{l}\text { Medicine, Maastricht } \\
\text { University Medical Center, }\end{array}$ & $\begin{array}{l}\text { Respiratory Medicine, } \\
\text { Mastricht University }\end{array}$ \\
Roy T. M. Sprooten, & Maastricht, The & Medical Center, PO-box \\
Gernot G. U. Rohde & Netherlands & 5800,6220 AZ Maastricht, \\
& & The Netherlands
\end{tabular}

\title{
An adolescent with chest pain
}

\section{Case Report}

An 18-year-old, otherwise healthy, young male reporting a 1-week history of muscular pain, a sore throat and a non-productive cough presented to the emergency room with acute chest pain and pain of the left shoulder. He also experienced some dizziness, without collapse, nausea or vomiting. He reported fever, but this was not objectively confirmed. There was no history of haemoptysis, wheezing, allergic reactions or weight loss. There was no significant family history of similar or other illnesses.

\section{Task 1}

What can cause acute chest pain in an otherwise healthy young adult?
Statement of Interest G. Rohde has received payment for lectures, including service on speaker bureaus, from: Pfizer, BI, Solvay, GSK, Essex Pharma, MSD, Novartis (all \$1-5k); and travel expenses $(\$ 1-5 k)$ from GSK. 


\section{Answer 1}

In this case you would suspect an infectious cause like a pneumonia or viral pleurisy/ pericarditis. A pulmonary embolus could also give some fever and a cough.

In the case of a young male you should always consider the possibility of a pneumothorax. Less obvious are cardiac ischaemia, myocarditis or pericarditis, myalgia or orthopaedic causes (table 1).

Aortic dissection is also a possible differential diagnosis (particularly in patients with Marfan's syndrome.

Table 1. Causes of chest pain

\begin{tabular}{|c|c|c|}
\hline Location & Differential diagnosis & Prevalence $^{\#} \%$ [2] \\
\hline \multirow[t]{4}{*}{ Pulmonary } & Pneumonia ${ }^{\top} /$ tracheabronchitis & 5 \\
\hline & Pleuritis & \\
\hline & Pulmonary embolus & \\
\hline & Pneumothorax & \\
\hline \multirow[t]{4}{*}{ Cardiovascular } & Myocarditis/pericarditis $₫$ & 16 \\
\hline & Cardiac ischaemia & \\
\hline & Aortic dissection & \\
\hline & Vasculitis & \\
\hline \multirow{6}{*}{$\begin{array}{l}\text { Chest wall/ } \\
\text { orthopaedic }\end{array}$} & Myalgia/cramps & 36 \\
\hline & Fracture & \\
\hline & Artritis/arthrosis & \\
\hline & Costochondritis/bursitis & \\
\hline & Neuropathic pain & \\
\hline & Cervical/thoracic disc disease & \\
\hline \multirow[t]{6}{*}{ Abdominal } & $\begin{array}{l}\text { Reflux/oesophagitis or oesophageal } \\
\text { dysmotility }\end{array}$ & 19 \\
\hline & Peptic ulcer & \\
\hline & Diafragm spasm & \\
\hline & Cholecystitis/choledocholithiasis & \\
\hline & Pancreatitis & \\
\hline & Nefrolithiasis & \\
\hline \multirow[t]{6}{*}{ Miscellaneous } & Autoimmune disease & Miscellaneous 16 ; psychiatric 8 \\
\hline & Malignancy & \\
\hline & Mediastinitis/mediastinal emphysema & \\
\hline & Somatoform disorders & \\
\hline & Anxiety disorders & \\
\hline & Intoxications (e.g. cocaine) & \\
\hline
\end{tabular}


On examination he had normal vital signs with a systolic/diastolic blood pressure of 135/ $65 \mathrm{mmHg}$, a heart rate of 80 beats $\cdot \mathrm{min}^{-1}$, a regular respiratory rate of 15 breaths $\cdot \mathrm{min}^{-1}$, a temperature of $37^{\circ} \mathrm{C}$, normal cardiac examination, normal breath sounds, normal chest percussion and no signs of a deep vein thrombosis (DVT). Ear, nose and throat examination revealed a right-sided submandibular enlarged lymph node, but no enlarged or exudative tonsils. His shoulder examination showed some tenderness in the region of the left deltoid muscle, but no signs of fracture or dislocation.

The laboratory data showed elevated white blood counts with a marked leftward shift, a high C-reactive protein (CRP) and elevated D-dimers (table 2). White blood cell counts were $15.2 \times 10^{9} \cdot \mathrm{L}^{-1}$, with $77 \%$ segmented granulocytes, $13 \%$ band cells (or stab cells); d-dimers were $1011 \mathrm{ng} \cdot \mathrm{mL}^{-1}$.

An ECG showed a sinus rhythm of $80 \cdot \mathrm{min}^{-1}$, right-sided bundle branch block and up sloping ST-segment in $\mathrm{V}_{3}-6$.

Chest radiograph (fig. 1) showed some increased dorsobasal density in the right lung (arrow), but no lobar infiltrate.

Table 2. Blood results

\begin{tabular}{lc}
\hline Blood component & \\
\hline Haemoglobin & $\begin{array}{c}8.6 \mathrm{mmol} \cdot \mathrm{L}^{-1} \\
\left(13.76 \mathrm{~g} \cdot \mathrm{dL}^{-1}\right)\end{array}$ \\
\hline White blood cells & $15.2 \times 10^{9} \cdot \mathrm{L}^{-1}$ \\
\hline Band forms \% & $\left.13200 \cdot \mathrm{mm}^{-3}\right)$ \\
\hline Neutrophils \% & 77 \\
\hline Lymfocyten \% & 1 \\
\hline Monocytes $\%$ & 0.62 \\
\hline Eosinophils $\%$ & 1011 \\
\hline D-dimers ng $\cdot \mathrm{mL}^{-1}$ & 239 \\
\hline CRP mg $\cdot \mathrm{L}^{-1}$ & 77 \\
\hline Creatinine $\mu \mathrm{mol} \cdot \mathrm{L}^{-1}$ &
\end{tabular}
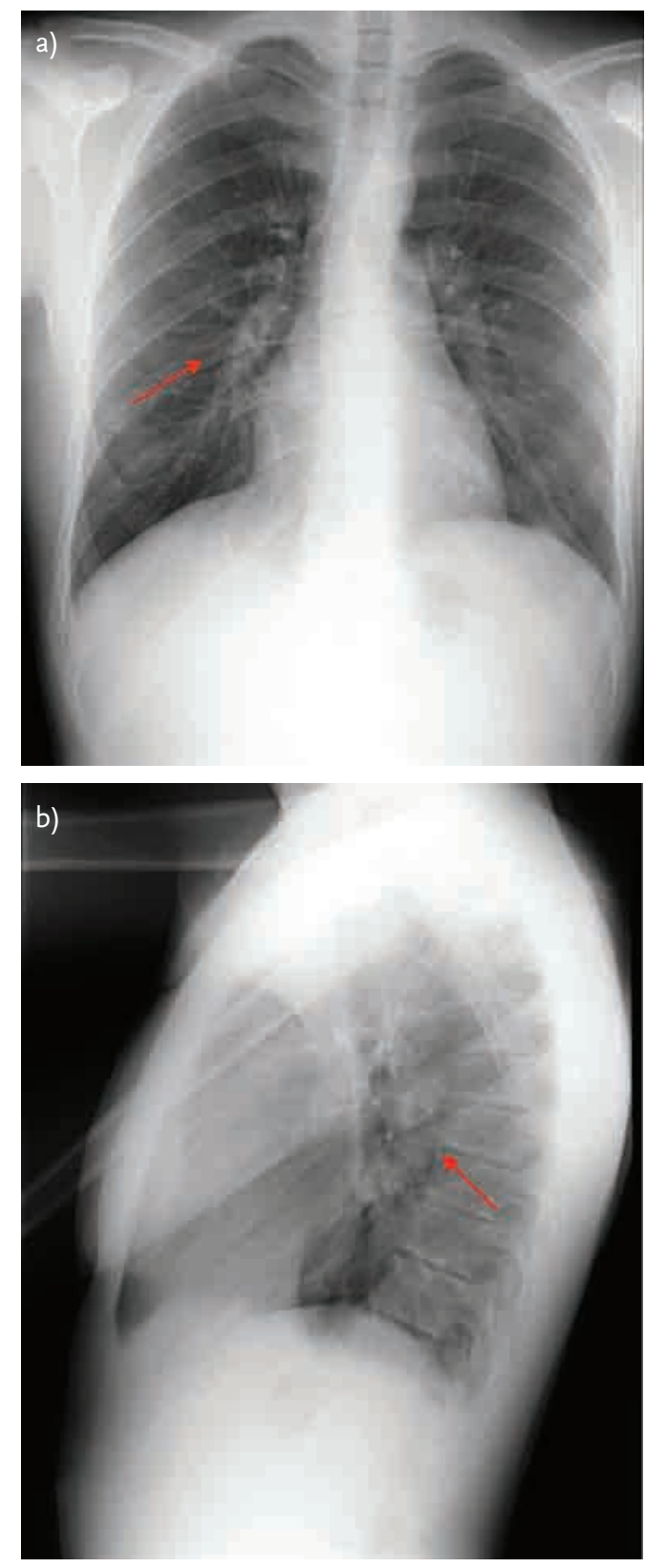

Figure 1

Chest radiograph showing slightly increased density parahilar right (a) and dorsobasal density (b).

\section{Task 2: What is your} (differential) diagnosis? 


\section{Answer 2}

Our differential diagnosis was an (upper) respiratory tract infection, pulmonary embolism, pleuritis or pericarditis (as he experienced the shoulder pain) or a lymphoma (as he had lymphadenopathy).

The patient was admitted to the hospital and was started on low molecular weight heparin since we considered a pulmonary embolism a plausible diagnosis and did not have an immediate computed tomography (CT) scan. As our patient had no fever at presentation in the emergency room, antibiotics were not started immediately.

\section{Task 3}

What can cause elevated D-dimers? 


\section{Answer 3}

D-dimer is a fibrin degradation product, which is generated from cross-linked fibrin. An elevated plasma concentration of D-dimer indicates recent or current intravascular blood coagulation and can be seen in several medical conditions (table 3).

Table 3. Causes of increased plasma levels of fibrin D-dimer

\section{Causes}

Arterial or venous thromboembolic disease

Disseminated intravascular coagulation or infection

Normal pregnancy or (pre)eclampsia

\section{Surgery or trauma}

Renal disease

Liver disease

\section{Malignancy}

Data from [3-5]

\section{Examples}

Stroke, myocardial infarction, DVT, pulmonary embolism

Can be seen in sepsis, malignancy and obstetric mishaps.

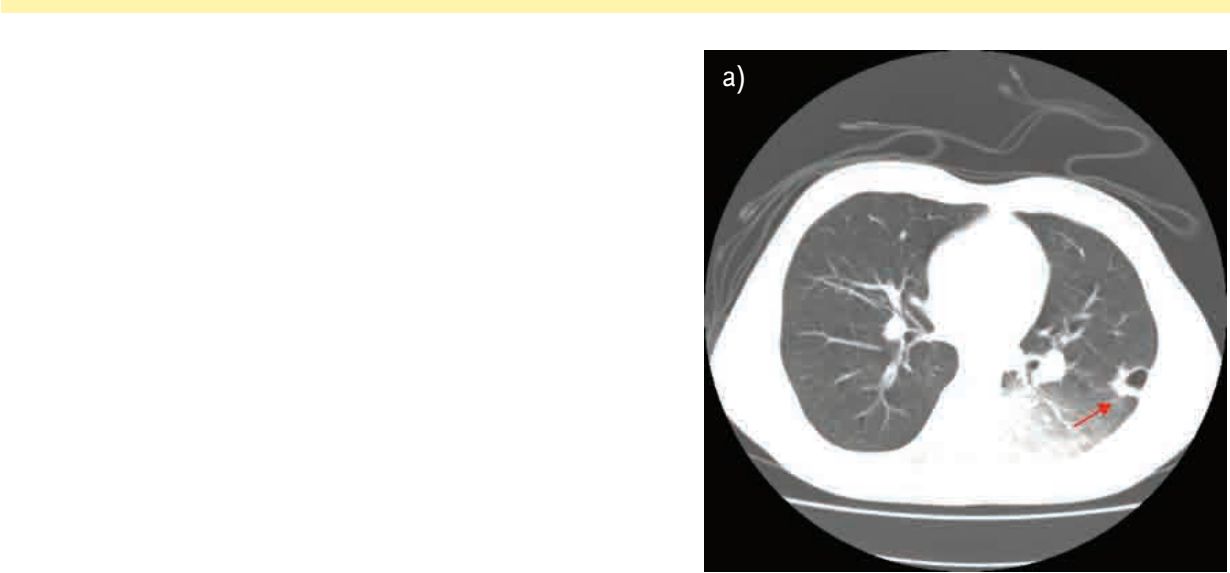

Nephrotic syndrome, renal failure

Due to decreased clearance
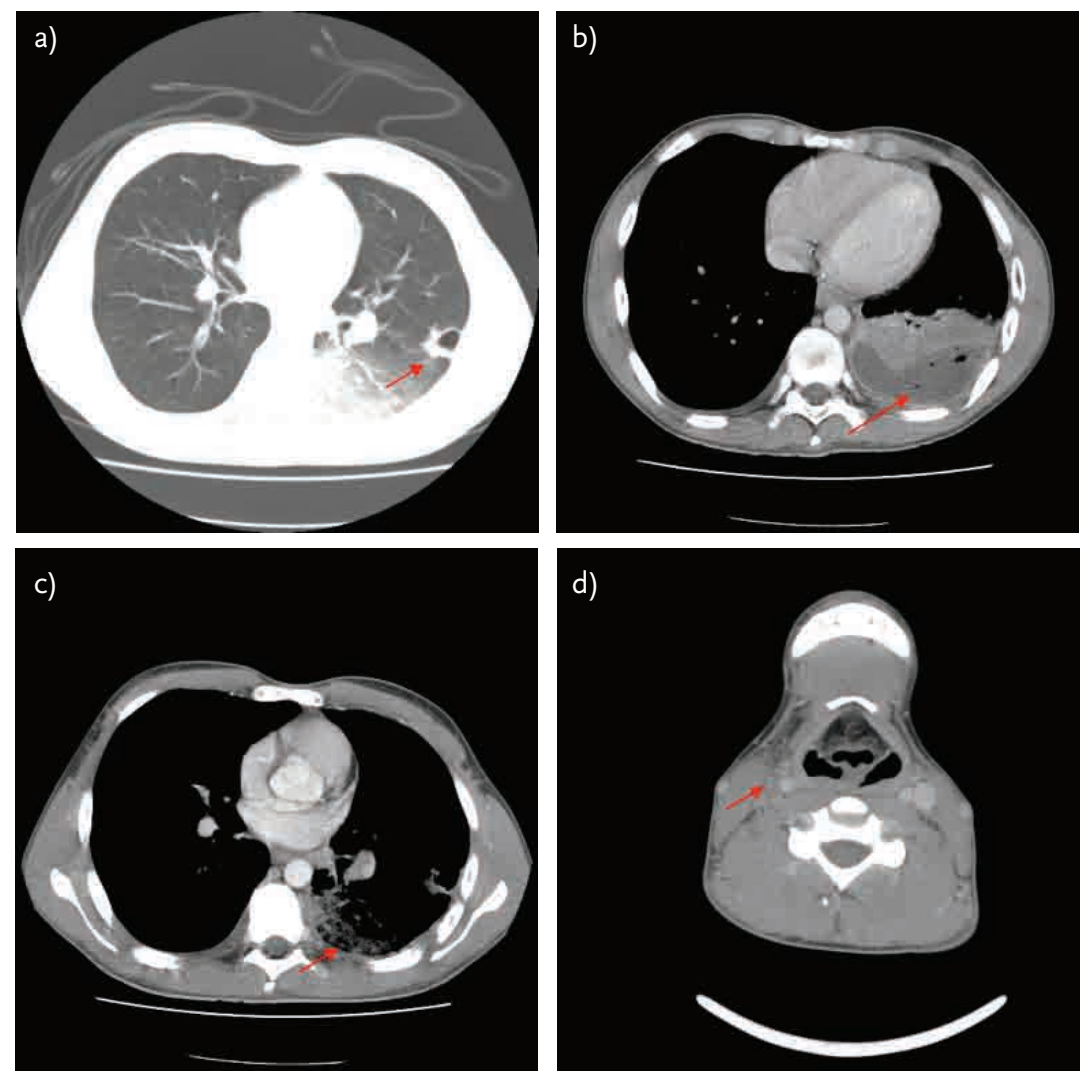

\section{Task 4}

Interpret the $\mathrm{CT}$ images

(fig. 2)
Figure 2

CT images. a) Cavitation left upper lobe, superior lingula and pulmonary infiltrates left lower lobe, superior segment, b) pulmonary infiltration with pleural effusion, c) pulmonary infiltrates, d) right-sided thrombosis of the internal jugular vein (land some cervical lymphadenopathy). 


\section{Answer 4}

The CT of the neck and thorax shows pulmonary infiltrates in the left upper and lower lobe, one of which has cavitation and a right-sided thrombosis of the internal jugular vein with cervical lymphadenopathy.

These findings were consistent with his chest and shoulder pain and cervical lymphadenopathy.

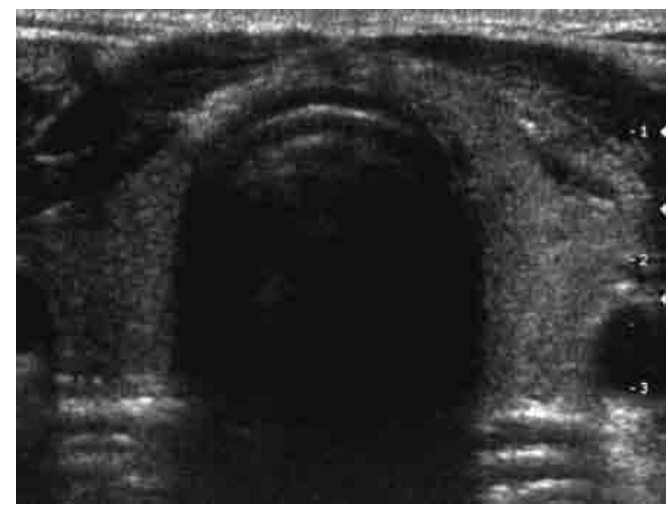

\section{Figure 3}

Thrombosis of the internal jugular vein. On ultrasound, reactive lymph nodes were seen, but these are not visible here. In case of thrombosis, no vein is visible in the region in which you would expect a vein.

$$
\begin{aligned}
& \text { Task } 5 \\
& \text { What can cause cavitating } \\
& \text { lesions in the lung? (fig. 3) }
\end{aligned}
$$

\section{Answer 5}

In this case an infectious cause seems most likely since our patient had a history of fever and malaise, and laboratory results that suggested an infection with elevated white blood cell counts and a high CRP. For example, cavitation and fever can be caused by a lung abscess, fungus, tuberculosis, pneumonia or septic (metastatic) embolism.

Considering our patient is a young male a congenital abnormality like a bronchogenic cyst is also possible. Histiocytosis $\mathrm{X}$ and lymphangioleiomyomatosis are also possible, although these last diagnoses look significantly different on CT.

Autoimmune diseases, like granulomatosis with polyangiitis (Wegener's) or rheumatoid arthritis, or a malignancy are less likely in this case. Our patient did not have any signs of kidney failure (creatinine $77 \mu \mathrm{mol} \cdot \mathrm{L}^{-1}$ ) and no history of skin abnormalities or epistaxis. As the diagnosis became clear within days, we did not carry out any further tests to exclude or confirm these diagnoses.

Since the CT scan showed bilobar infiltrates, antibiotic treatment was started (moxifloxacin $400 \mathrm{mg}$ once daily). Moxifloxacin was chosen because it can be given orally without sacrificing bioavailability and it can also be used to treat an atypical bacterial pneumonia.

3 days later blood cultures yielded Fusobacterium necrophorum, confirming the diagnosis of Lemierre's syndrome (septic thrombophlebitis (task 3), metastatic abcesses (task 5) and blood cultures growing anaerobic Gram-negative bacilli). Intravenous antibiotic treatment with benzyl penicillin $(6 \times 1.2 \mathrm{~g})$ and metronidazol $(3 \times 750 \mathrm{mg})$ was started.

Unfortunately our patient did not make a speedy recovery. He had a persistent subfebrile temperature (under paracetamol and ibuprofen) and elevated CRP. A new CT scan of the thorax was made to exclude a lung abscess or empyema.

Unfortunately, the new CT of the thorax showed a left-sided pleural effusion, surrounded by pulmonary infiltrates, and the cavitation of the left upper lobe had become larger. 


\begin{tabular}{|c|c|}
\hline Cause & Examples \\
\hline $\begin{array}{l}\text { Infection } \\
\text { Pneumonia } \\
\text { Lung abscess } \\
\text { Septic (metastatic) embolism }\end{array}$ & $\begin{array}{l}\text { Bacteria e.g. Actinomyces spp., Nocardia spp., Mycobacterium } \\
\text { spp.; Fungi e.g. Aspergillus spp., Cryptococcus spp., } \\
\text { pneumocystosis; Parasites e.g. Echinococcus spp. }\end{array}$ \\
\hline \multirow[t]{5}{*}{ Autoimmune disease } & Granulomatosis with polyangiitis \\
\hline & Sarcoidosis \\
\hline & Rheumatoid arthritis \\
\hline & Ankylosing spondylitis \\
\hline & Systemic lupus erythematosus \\
\hline \multirow[t]{4}{*}{ Malignancy } & Primary lung cancer, mostly squamous cell \\
\hline & Lymphoma \\
\hline & Lung metastasis \\
\hline & Kaposi's sarcoma \\
\hline \multirow{3}{*}{$\begin{array}{l}\text { Congenital abnormality/acquired } \\
\text { lung disease }\end{array}$} & Bronchogenic cyst \\
\hline & Histiocytosis X (langerhans histiocytosis) \\
\hline & Lymphangioleiomyomatosis \\
\hline Vascular disease & Pulmonary embolism (septic or aseptic) \\
\hline BOOP/COP & Due to e.g. medication, radiotherapy or autoimmune disease \\
\hline
\end{tabular}

Data from [6]. BOOP: bronchiolitis obliterans organising pneumonia; COP: cryptogenic organising pneumonitis.

To exclude emphysema, a diagnostic thoracentesis was performed and showed some cloudy yellow effusion. The Gram stain was negative, as was the culture. The antibiotics were continued. The patient clinically improved during his stay in hospital.

He was discharged 2 weeks after presentation in the emergency room with oral antibiotics (for a further 4 weeks) and made a slow, but complete recovery.

\section{Discussion}

This report describes a young male with chest pain, fever, coughing and a sore throat. On the CT scan there was a thrombosis of the right internal jugular vein, there were multiple enlarged lymph nodes on the left and right, pulmonary infiltrates, one of which had cavitation, but no pulmonary embolisms. There seemed to be septic embolisms.

A thrombophlebitis of the internal jugular vein with septicaemia and metastatic infections after a head or neck infection with F. necrophorum is pathognomonic for Lemierre's syndrome.

The metastatic infections are predominantly found in the lungs and joints [7, 8]. $F$. necrophorum is an anaerobic Gram-negative bacillus and a constituent of the normal oropharyngeal (but also gastrointestinal and genitourinary) microflora. After mucosal invasion, several virulence factors, such as haemolysin, play a role in the complex pathogenesis of Lemierre's syndrome. Haemolysin lyses erythrocytes and, in this way, reduces oxygen transport to the site of the infection [7]. F. Necrophorum produces haemagglutinin, which causes platelet aggregation that can lead to diffuse intravascular coagulation and thrombocytopenia, but also to thrombosis $[8,9]$.

Evidence exists that potentially links Epstein-Barr virus (EBV) and F. necrophorum. The mechanism by which the two pathogens are interconnected is unknown. Possible mechanisms include altered mucosa, lymphatic obstruction and increased penetration of 
bacteria in the tonsillar epithelium in patients with mononucleosis [10]. In this case there was no evidence of a recent EBV infection (EBV IgM $\left.<_{4} \mathrm{IE} \cdot \mathrm{L}^{-1}\right)$.

Typically, patients are in their first three decades of life (with $75 \%$ aged between 16 25 years), but ages range from 2 months to 78 years. The male to female ratio is 1:1 [8]. Most patients have no previous medical history.

At initial presentation, tonsils can appear exudative, hyperaemic, ulcerated or normal. These signs can disappear without antibiotics by the time septic thrombophlebitis or metastatic complications occur. This usually happens 1-3 weeks after the primary infection [10].

The incidence is approximately one per million per year, but it has a mortality of 5$10 \%[7,9,10]$. Before the development of antibiotics this syndrome had a rapidly fatal course. Any antimicrobial regimen should include a $\beta$-lactam antibiotic. Additionally, oral streptococci should be targeted [10]. The optimal treatment is a combination of penicillin $1.2 \mathrm{~g}$ every $4 \mathrm{~h}$ (or ceftriaxone $2 \mathrm{~g}$ i.v. every $24 \mathrm{~h}$ ) and metronidazol $500 \mathrm{mg}$ every $8 \mathrm{~h}$ (100\% sensitivity, excellent penetration) or monotherapy with clindamycine $600 \mathrm{mg}$ every $8 \mathrm{~h}$ for $\geqslant 6$ weeks. Once the infection is controlled clinically, therapy can be completed orally [7, 9, 10]. Antimicrobial resistance among $F$. necrophorum is rare [10].

Surgical debridement or drainage of the infected tissue can be necessary [7, 9, 10].

The use of anticoagulation is controversial. Although it is commonly used for other illnesses with septic emboli, its role in Lemierre's syndrome is unclear. It is generally not recommended, except in the case of cavernous sinus thrombosis [7, 8 10].

Contrast-enhanced CT of the neck is the best choice for establishing the diagnosis of thrombosis of the internal jugular vein [7]. It can also help to exclude other causes of swelling, pain or fever. Alternatively, ultrasound can be used.

\section{Conclusion}

Lemierre's syndrome is a rare, but serious complication of head or neck infection by Fusibacterium, mostly affecting previously healthy young adults. It is potentially life threatening and a prompt recognition of the triad of symptoms: internal jugular vein thrombophlebitis; septicaemia; and metastatic infections. Antibiotic treatment is important to make a full recovery and surgical debridement may be necessary.

\section{References}

1. Spiro SG, Silvestri GA, Agustí A. Clinical Respiratory Medicine. 4th Edn. Philadelphia: Saunders, 2012.

2. Klinkman MS, Stevens D, Gorenflow DW. Episodes pf care for chest pain: a preliminary report from MIRNET. Michigan Research Network. J Fam Pract 1994; 38: 345-352

3. Adam SS, Key NS, Greenberg CS. D-dimer antigen: current concepts and future prospects. Blood 2009; 113: 2878-2887.

4. Preloznik Zupan I, Sabovic M, Salobir B, et al. Characterization of the pro-thrombotic state in CAPD patients. Ren Fail 2008; 30: 597-602.

5. Saray A, Mesihovic R, Vanis N, et al. Clinical significance of haemostatic tests in chronic liver disease. Med Arh 2012; 66: 231-235.

6. Gadkowski LB, Stout JE. Cavitary pulmonary disease. Clin Microbiol Rev 2008; 21: 305-333.

7. Dool H, Soetekouw R, van Zanten M, et al. Lemierre's syndrome: three cases and a review. Eur Arch Otorhinolaryngol 2005; 262: 651-654.

8. Karkos PD, Asrani S, Karkos CD, et al. Lemierre's syndrome: a systematic review. Laryngoscope 2009; 119: 1552-1559.

9. Redford MR, Ellis R, Rees C). Fusobacterium necrophorum infections associated with portal vein thrombosis. J Med Microbiol 2005; 54: 993-995.

10. Kuppalli K, Livorsi D, Talati NJ, et al. Lemierre's syndrome due to Fusobacterium necrophorum. Lancet Infect Dis 2012; 12: 808-815. 